\title{
Assessment of the Dynamic Behavior of Beam-to-Column Connections in Steel Pallet Racks under Cyclic Load: Numerical Investigation
}

\author{
Zhi-Jun Lyu $\mathbb{C D}^{1,2}$ Meng Wu, ${ }^{1,2}$ YuXin Huang $\mathbb{D}^{1,2}$ YiMing Song $\mathbb{D}^{1,2}$ and Xiong Cui ${ }^{3,2}$ \\ ${ }^{1}$ College of Mechanical Engineering, Donghua University, Shanghai 201620, China \\ ${ }^{2}$ Shanghai Engineering Research Centre of Storage \& Logistics Equipment, Shanghai 201611, China \\ ${ }^{3}$ Shanghai Jingxing Storage Equipment Engineering Co., Ltd., Shanghai 201611, China
}

Correspondence should be addressed to Zhi-Jun Lyu; lvzj@dhu.edu.cn

Received 1 June 2018; Accepted 30 August 2018; Published 11 November 2018

Academic Editor: Tadeh Zirakian

Copyright (c) 2018 Zhi-Jun Lyu et al. This is an open access article distributed under the Creative Commons Attribution License, which permits unrestricted use, distribution, and reproduction in any medium, provided the original work is properly cited.

Steel pallet racks (SPRs) are characterized by boltless beam-column connections (BCCs). The role of BCCs becomes more significant during hazardous conditions such as earthquakes. Due to the great number of beam-end connector types and member geometries, the accurate evaluation of their structural behavior, especially under seismic loads, seems to be very difficult to perform so far. In this paper, the authors present results of simulation based on cyclic tests on different types of industrial rack joints by the finite element (FE) modeling of connections. This paper mainly investigates the BCC geometrical factors affecting the dynamic behavior of braced racks. Design indications are consequently provided in order to guarantee a globally homogenous ductility among different BCC configurations under seismic actions.

\section{Introduction}

Opposite of what happens for traditional civil engineering structures, the material of steel member for high-rise steel pallet racks (SPR) is thin and lightweight, and storage pallet racking systems can usually carry live load many times larger than the dead load with an extraordinary height [1]. However, this well-recognized advantage is counterbalanced by a structural response that is too complex to predict, especially under earthquakes. Main reason maybe that dynamic behavior of pallet racks is affected by not only the particular geometry of their structural members made by high slender thin-walled, open-section profiles (hence leading to local, global and even distortional buckling problems) but also beam-tocolumn connections representing a strong nonlinear behavior. It is generally considered that the beam-end connector is the most critical part of the assembly which determines the dynamic stability of SPR in the down-aisle direction [2].
In view of its importance, the most recent design codes, such as that of the RMI [3], EN15512 [4], and AS4084 [5], suggest individual experimental testing and define testing protocols with a marginal difference to predict the momentrotation $(M-\theta)$ behavior of beam-to-column connections. Bajoria and Talikoti [6] adopted a double cantilever test method and compared with the single side cantilever beam test method. After that, the finite element simulation model was established based on the test. The superiority of the double cantilever test method and the feasibility of the finite element simulation were verified. Monotonic experimental tests were conducted in [7] to investigate the flexural behavior of connections under hogging loading in a single cantilever test setup. Several groups of beam-upright connections with different constructional details, such as the upright's profile, the thickness, and the number of tabs in the beam-end connector, were investigated. These tests highlighted that the failure mode of connections mainly depends on the relative thickness between the upright and the beamend connector. Bernuzzi and Castiglioni [8] performed 
a series of 11 monotonic and 11 cyclic tests on two different types of beam-to-upright connections used in Europe. The experimental results obtained from the monotonic tests indicated that the connections were characterized by significant ductile behavior. Federico Gusella et al. [9] presented results of monotonic and cyclic tests on four different types of industrial rack joints to illustrate the influence of the welding layout of beam-end connectors on the structural response and failure mode of joints. In addition, as one of the universal methods for evaluating seismic performance of connections, Tang and Chouw [10] describe a series of full-scale shake table tests performed to extend the understanding of the uplift behavior of interlocking columns. It is no doubt that experimental investigations are expensive and difficult to repeat. Therefore, a suitable solution is to derive a particular uniform $M-\theta$ relationship for each connection type in terms of geometric parameters through finite element (FE) modeling. The structural behavior of rack connections has been also investigated by finite element numerical models. In [11], results of experimental tests on rack beam-end connections using both a cantilever and a double cantilever test setup were compared with those obtained through nonlinear finite element analyses, which were found to match well with the full-scale frame tests. The influence of the modeling of beam-column joints on the overall structural response of pallet racks was investigated in the numerical studies developed in [12], where frame models with semirigid joints were suggested, and in [13], where the importance of taking into account the cyclic behavior of connections to perform more reliable dynamic nonlinear analyses was underlined. Markazi et al. [2] conducted tests on the four different types of commercially available beamend connectors to determine the parameters governing an efficient beam-end connector. Carlos [14] presented experimental findings about the beam-column connection under static and cyclic loads. The similarity of the static and cyclic failure modes indicate that the failure was controlled entirely by the connecting elements. Yin et al. [15] adopted some indexes such as the energy dissipation capability and the displacement ductility factor to explore the bearing capacity and energy dissipation of several variations of speed-lock connections of cold-formed steel storage racks. Mashaly et al. [16] presented a simple and accurate threedimensional (3D) finite element model (FE) capable of predicting the actual behavior of beam-to-column joints in steel frames subjected to lateral loads. In this paper, the surface-to-surface element was used instead of node-tonode element to enhance the model. The FE results showed good correlation with the experimental one. However, reports about relationship between the structure features of SPR BCCs and its dynamic behavior have not been seen so far.

Based on the cyclic behavior of SPR BCC's test, this paper presents the results of simulation performed on the specimens of different BCC configurations using FE software ABAQUS. In terms of hysteretic loop and backbone curve, this paper discusses the structure geometrical factors affecting the dynamic behavior of braced racks. Moreover, the authors quantify the global ductility and stiffness deterioration of specimens in comparison with the design standard values. Finally, the paper highlights the vulnerability of braced racks to connection failures and provides design indications for a more ductile rack design with good BCC configurations.

\section{Cyclic Experiment Investigation}

2.1. Connection Types and Specimen Details. In this study, two tests were carried out in order to declare the accuracy of the results obtained by the finite element models established using FE software ABAQUS. All the test specimens including columns, beams, and beam-end connectors were manufactured from cold-formed steel. The material properties of them are given in Table 1.

In steel pallet racks, the rivet connection is commonly used because of its flexible installation, as shown in Figure 1. Therefore, in this study, the rivet connection was adopted to identify the effects of various parameters which may affect the overall seismic performance of beam-to-column connections. Details of the rivet connection are shown in Figure 2. These specimens were distinguished by two different columns and beam depths. Each specimen consists of a $400 \mathrm{~mm}$ long column and a $750 \mathrm{~mm}$ long beam, which was manufactured in accordance with the FEM 10.2.08 [17]. M100 and M120 columns and B80 and B100 beams were selected according to the actual situation of enterprise. Both beam-end connectors have three rivets. Detailed specimen parameters are given in Table 2.

2.2. Test Setup and Instrumentation. In this study, the cantilever test method was adopted to obtain the hysteresis curve of the beam-to-column connections. The test setup consists of a testing frame, a loading device, and displacement transducers, as illustrated in Figure 3. The column was fixed on the column welding plate, and the beam was connected to the column by the connector. In the test, the measuring plate used to reflect the rotation angle $\theta$ was installed on the beam, and two displacement transducers were installed on the plate for collecting the variation of deflection $\delta$. The loading point had been applied at a distance of $400 \mathrm{~mm}$ from the surface of the upright. During the test, the loading device imposed a preload on the beam in advance, which is $10 \%$ of the expected failure load and then unloaded. The load was gradually increased till the connector failed. During the test, the data measured by the displacement transducers and pressure sensors were recorded by the data acquisition card, and then $M-\theta$ curves were generated by processing the data.

2.3. Cyclic Loading Protocol. The cyclic loading protocol was based on the variable amplitude load control mode. Before yielding, the load was increased by $1000 \mathrm{~N}$ for each level, and the load was repeated twice. After yielding, the load was still increased $1000 \mathrm{~N}$ every step but repeated once. The cyclic loading protocol is illustrated in Figure 4. When the force was downward, the direction was seen as positive, the angle $\theta$ 
TABLE 1: Material properties of specimens.

\begin{tabular}{lccc}
\hline Young's modulus, $E(\mathrm{GPa})$ & Poisson's ratio, $\mu$ & Yield strength, $f_{\mathrm{y}}(\mathrm{MPa})$ & Ultimate strength, $f_{\mathrm{u}}(\mathrm{MPa})$ \\
\hline 210 & 0.3 & 235 & 390 \\
\hline
\end{tabular}

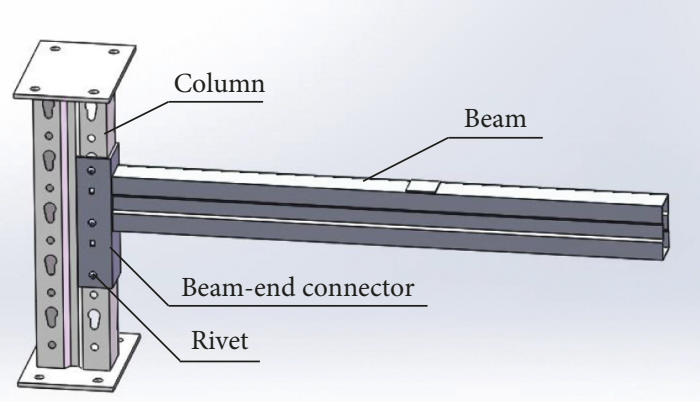

Figure 1: The rivet connection.

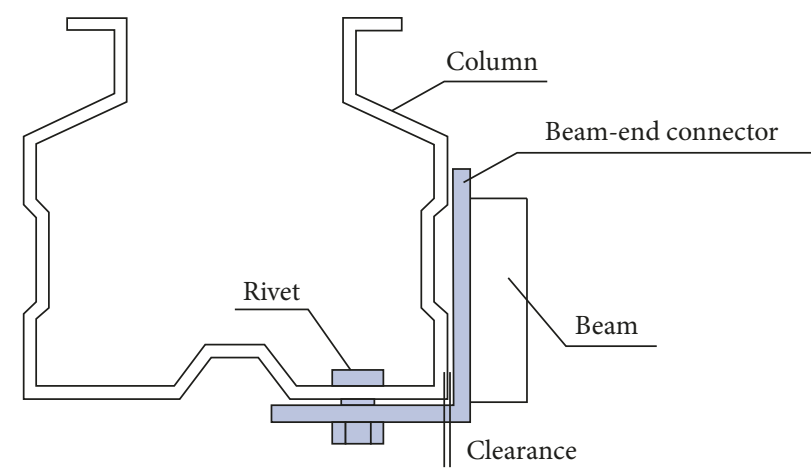

FIgURE 2: Details of the rivet connection.

TABle 2: Detailed specimen parameters.

\begin{tabular}{lccccc}
\hline & Column & Column thickness $(\mathrm{mm})$ & Beam & Number of rivets & Beam-end connector thickness $(\mathrm{mm})$ \\
\hline Test 1 & M120 & 2.5 & B100 & 3 & 4 \\
Test 2 & M100 & 2.5 & B80 & 3 & 4 \\
\hline
\end{tabular}
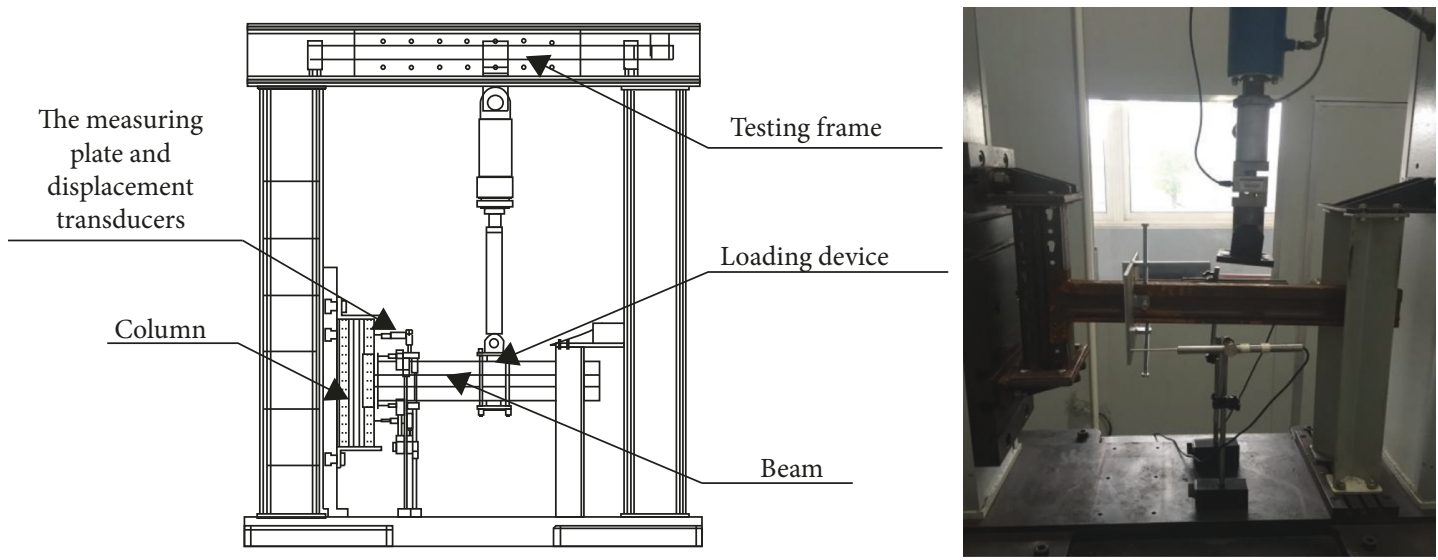

Figure 3: The test setup. 


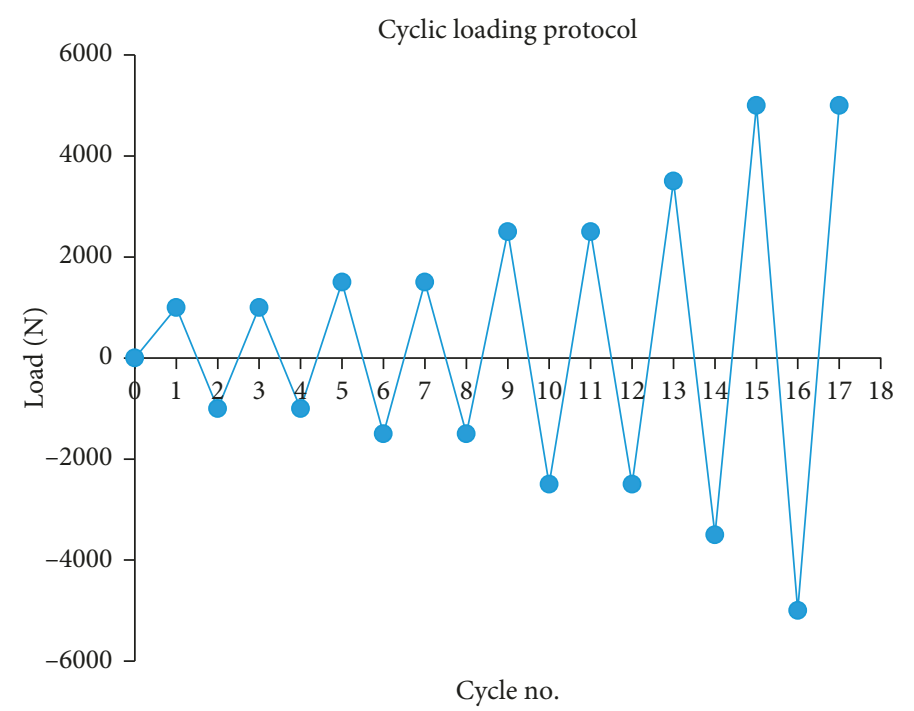

FIGURE 4: The cyclic loading protocol.

was negative, the load was negative, and vice versa. When the sample's connector, welding spot, or column holes appeared obviously damaged, the test stopped.

\section{Finite Element Simulation}

In this study, the three-dimensional model of different combinations of beam-to-column connections was developed to evaluate the effect of different parameters. In this paper, six parameters that might affect the seismic performance of the beam-to-column connections were selected, such as column thickness, beam depth, thickness of the beam-end connector, and the welding position of beam to the beam-end connector. Details of specimens are listed in Table 3. Specimens A only made changes to the beam depth to analyze the influence of beam depth on the seismic performance of beam-to-column connections. Similarly, specimens B, C, D, E, and F were used to analyze the influence of column thickness, thickness of the beam-end connector, the welding position of the beam, number of rivets, and clearance between column and beam-end connector, respectively. To ensure the accuracy, the details such as the flange's opening, the stiffener, and the fillet were reserved. Then, a finite element model was established using the commercial FE software ABAQUS.

3.1. Material Properties and Element Types. Different combinations of beam, column, and beam-end connector assemblies were modeled. The material properties of all the three components listed in Table 1 were used for FE modeling (FEM). Element C3D10 (a 10-node quadratic tetrahedron) was used for all the three parts of an assembly.

3.2. Connection Modeling and Surface Interaction. Contact nonlinearity was incorporated into the FE model by defining the interactions among column, beam-end connectors, and rivets. The surface-to-surface interactions (front and side) between the column and the beam-end connector were defined through tangential frictionless behavior, as shown in Figure 5(a). Similarly, the surface-tosurface interactions between the column and rivets were defined in two ways: (i) normal hard contact, as shown in Figure 5(b), and (ii) tangential frictionless contact, as shown in Figure 5(c). The former was defined to avoid the relative movement between the surfaces of the column and the rivet, whereas the latter was defined to restrain the sideways movement (normal to longitudinal axes) of the column.

3.3. Loading and Boundary Conditions. Loading and boundary conditions were consistent with the test setup. In the experimental setup, both column ends were clamped and the column moves only up and down as a rigid body. Therefore, similar boundary conditions were applied to end of beams and the column. Upper and lower column ends are pinned support, that is, three degrees of freedom of $X, Y$, and $\mathrm{Z}$ were constrained, and freedom in $\mathrm{Z}$ direction was constrained for the beam. The concentrated force has been applied at a distance of $400 \mathrm{~mm}$ from the column's face. Similar loading procedure was adopted for FE analysis.

\subsection{Simulation Results}

3.4.1. Failure Mode. Comparing experimental results with simulation results, failure modes of the FE model exhibited close agreement with the experimental results. Under the cyclic load, holes were gradually deformed due to tension and compression of rivets and swinging of beams. After test, column holes appeared as gaps and rivets and the beam-end connector underwent obvious deformation. A comparison of failure modes in both experimental and FE analysis is presented in Figure 6. Deformation of the abovementioned components together resulted in failure of the beam-column connection. 
TABLE 3: Details of specimens.

\begin{tabular}{|c|c|c|c|c|c|c|c|c|}
\hline & ID & Column & $\begin{array}{l}\text { Column thickness } \\
(\mathrm{mm})\end{array}$ & $\begin{array}{l}\text { Thickness of beam-end connector } \\
\text { (mm) }\end{array}$ & $\begin{array}{l}\text { Beam } \\
\text { depth }\end{array}$ & $\begin{array}{c}\text { Beam } \\
\text { position }\end{array}$ & $\begin{array}{c}\text { Number of } \\
\text { rivets }\end{array}$ & Clearance \\
\hline \multirow{4}{*}{ A } & A-1 & M120 & 2.5 & 4 & $\mathrm{~B} 80$ & Upper & 3 & 1 \\
\hline & $\begin{array}{c}\text { A-2 } \\
\text { (standard) }\end{array}$ & M120 & 2.5 & 4 & $\mathrm{~B} 100$ & Upper & 3 & 1 \\
\hline & A-3 & M120 & 2.5 & 4 & B120 & Upper & 3 & 1 \\
\hline & B-1 & M120 & 2 & 4 & $\mathrm{~B} 100$ & Upper & 3 & 1 \\
\hline \multirow[t]{2}{*}{ B } & $\begin{array}{c}\text { B-2 } \\
\text { (standard) }\end{array}$ & M120 & 2.5 & 4 & $\mathrm{~B} 100$ & Upper & 3 & 1 \\
\hline & B-3 & M120 & 3 & 4 & B100 & Upper & 3 & 1 \\
\hline \multirow[t]{2}{*}{$\mathrm{C}$} & $\begin{array}{c}\mathrm{C}-1 \\
\text { (standard) }\end{array}$ & M120 & 2.5 & 4 & $\mathrm{~B} 100$ & Upper & 3 & 1 \\
\hline & C-2 & M120 & 2.5 & 4 & $\mathrm{~B} 100$ & Upper & 4 & 1 \\
\hline \multirow{3}{*}{$\mathrm{D}$} & $\begin{array}{c}\text { D-1 } \\
\text { (standard) }\end{array}$ & M120 & 2.5 & 4 & B100 & Upper & 3 & 1 \\
\hline & D-2 & M120 & 2.5 & 4 & B100 & Middle & 3 & 1 \\
\hline & D-3 & M120 & 2.5 & 4 & B100 & Lower & 3 & 1 \\
\hline \multirow{3}{*}{$\mathrm{E}$} & $\begin{array}{c}\text { E-1 } \\
\text { (standard) }\end{array}$ & M120 & 2.5 & 4 & B100 & Upper & 3 & 1 \\
\hline & E-2 & M120 & 2.5 & 5 & B100 & Upper & 3 & 1 \\
\hline & E-3 & M120 & 2.5 & 6 & B100 & Upper & 3 & 1 \\
\hline \multirow{3}{*}{$F$} & $\begin{array}{c}\text { F-1 } \\
\text { (standard) }\end{array}$ & M120 & 2.5 & 4 & B100 & Upper & 3 & 1 \\
\hline & F-2 & M120 & 2.5 & 4 & B100 & Upper & 3 & 2 \\
\hline & F-3 & M120 & 2.5 & 4 & B100 & Upper & 3 & 3 \\
\hline
\end{tabular}

3.4.2. Hysteretic Loop and Backbone Curve. Based on experimental data, the nondimensional moment-rotation curves are drawn in Figure 7. The hysteresis loops show a $\mathrm{z}$-shape during loading. Along with the increase of force, the slope of hysteretic loop keeps changing and decreasing and strength and stiffness decreasing. The maximum bending moment in the first cycle of each group is greater than in subsequent two cycles because of the deterioration undergone by the connector device.

Backbone curve analysis is one of the methods to analyze seismic performance. For each connection, the backbone curve is a line that connects peak points of the cyclic moment-rotation curve. The backbone curves from hysteretic moment-rotation responses are shown in Figure 8. By comparison, it can be found that experimental results are in close agreement with the backbone curves of simulation results, but there are greater errors in individual points and mainly appeared in the latter part of cyclic load. On the other hand, to achieve the same rotation of the backbone curves, the bending moment required by the finite element model is slightly larger than that of the test. The main reason for the error is that the finite element model does not consider geometric errors and initial defects, which will cause backbone curve difference.

3.4.3. Rotation Ductility Factor. Ductility is an important index to evaluate seismic performance of structure [15]. The ductility factor $\mu$ is usually defined by the following equation:

$$
\mu=\frac{\theta_{\mathrm{u}}}{\theta_{\mathrm{y}}},
$$

where $\theta_{\mathrm{u}}$ is the limit state (e.g., ultimate) rotation and $\theta_{\mathrm{y}}$ is the yielding rotation.

In this study, because there is no definite yielding point in Figure 8, to figure out the yielding rotation, a revised general yielding moment method (GYMM) [18] is employed. A schematic sketch of the method is shown in Figure 9. Based on a backbone curve of moment-rotation relation in Figure 9, $\mathrm{OH}$ is a line that represents the elastic theory value and intersects with the horizontal line of the ultimate load $\mathrm{C}$ at $\mathrm{H}$. Then, a vertical line passing $\mathrm{H}$ intersects with backbone curve at $\mathrm{A}$. Point $\mathrm{H}^{\prime}$ is the intersection point of line $\mathrm{OA}$ and line $\mathrm{CH}$. Then, a vertical line passing $\mathrm{H}^{\prime}$ intersects with the backbone curve at $\mathrm{B}$, which is the yielding point. The horizontal axis value of point $\mathrm{B}$ is identified as the yielding rotation $\theta_{\mathrm{y}}$. Limit state rotation $\theta_{\mathrm{u}}$ is the value that corresponds with the limit state (or ultimate) moment $M_{\mathrm{u}}$ [15]. Then, the ductility factors of all connections for both positive and negative loading are calculated and provided in Table 4.

3.4.4. Stiffness Deterioration Index. For cyclic loading, displacement increases gradually to the limit state rotation $\theta_{\mathrm{u}}$ while stiffness reduces with cycles. This stiffness deterioration can be calculated from the hysteresis loops. The relationship of stiffness $K$ and rotation $\theta$ can be analyzed based on the data. As shown in Figure 10, polyline $C^{\prime}-B^{\prime}-A^{\prime}$ $\mathrm{O}-\mathrm{A}-\mathrm{B}-\mathrm{C}$ is a simplified "trifold" backbone curve after dimensionless processing. The slope $K_{1}$ of $\mathrm{DE}$ is positive unloading stiffness. In order to calculate the stiffness deterioration index, relative stiffness $K_{1} / K_{0}$ and relative 


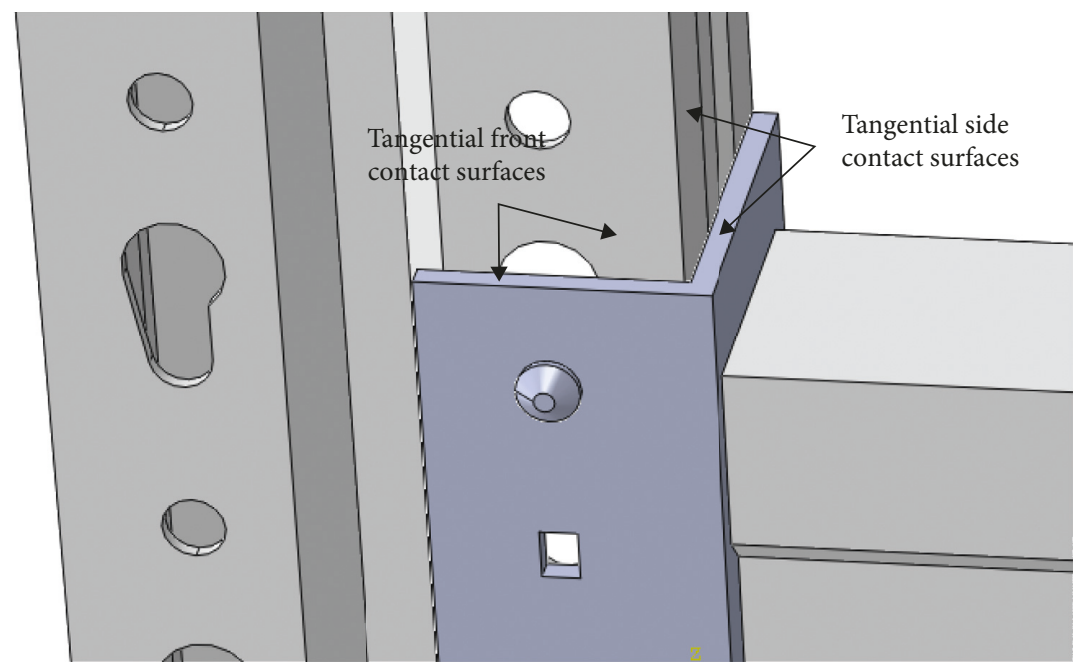

(a)

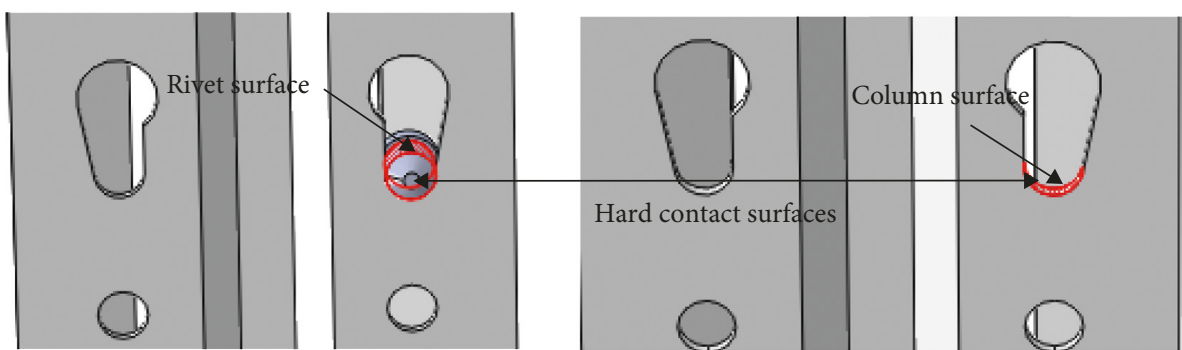

(b)

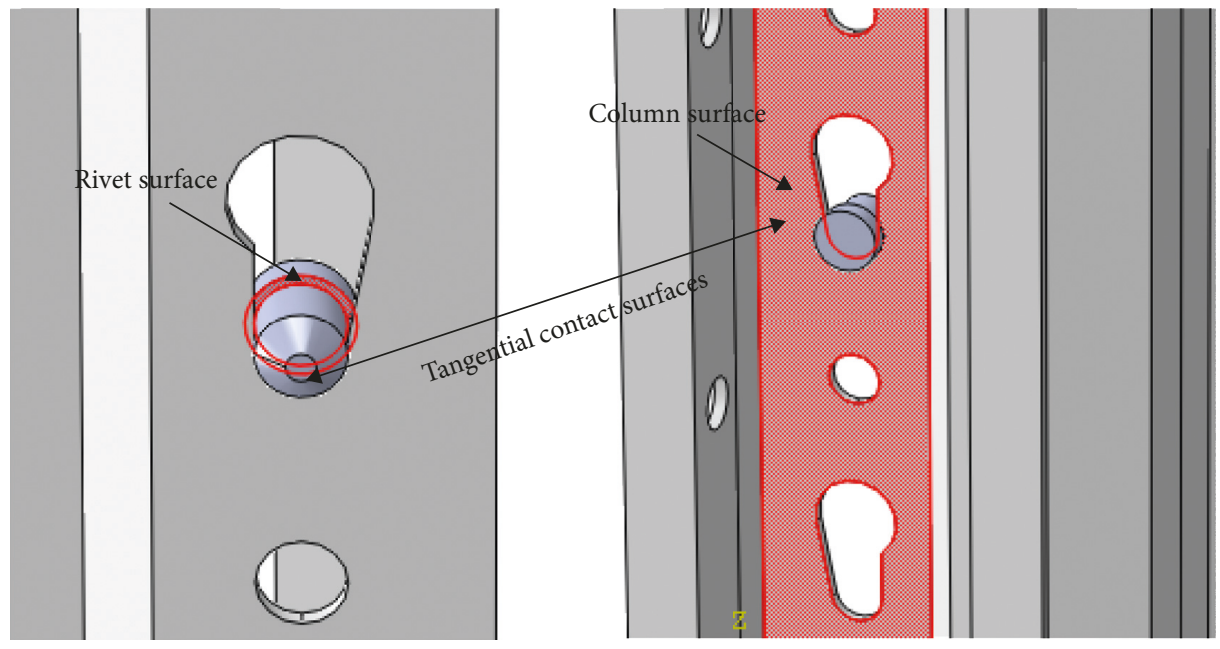

(c)

Figure 5: Surface-to-surface interaction among components. (a) Interactions between column and the beam-end connector. (b) Normal hard contact between column and rivets. (c) Tangential frictionless contact between column and rivets.

rotation $\Delta_{1} / \Delta_{\mathrm{u}}^{+}$need to be calculated, where $\Delta_{1}$ is the rotation corresponding to the unloading point of each hysteresis loop, $K_{0}$ is initial stiffness, and $\Delta_{\mathrm{u}}^{+}$is the rotation corresponding to the positive yield point. Similarly, $K_{2}, K_{3}$, and $K_{4}$ are negative loading stiffness, negative unloading stiffness, and positive loading stiffness, respectively. $K_{2} / K_{0}$,
$\Delta_{2} / \Delta_{\mathrm{u}}^{+} ; K_{3} / K_{0}, \Delta_{3} / \Delta_{\mathrm{u}}^{-} ;$and $K_{4} / K_{0}, \Delta_{4} / \Delta_{\mathrm{u}}^{-}$are calculated, respectively.

In the study, taking M120 column as an example, the stiffness degeneration curve is fitted using MATLAB lsqcurvefit function, and the fitted curves are shown in Figure 11. Calculate the stiffness deterioration as follows: 

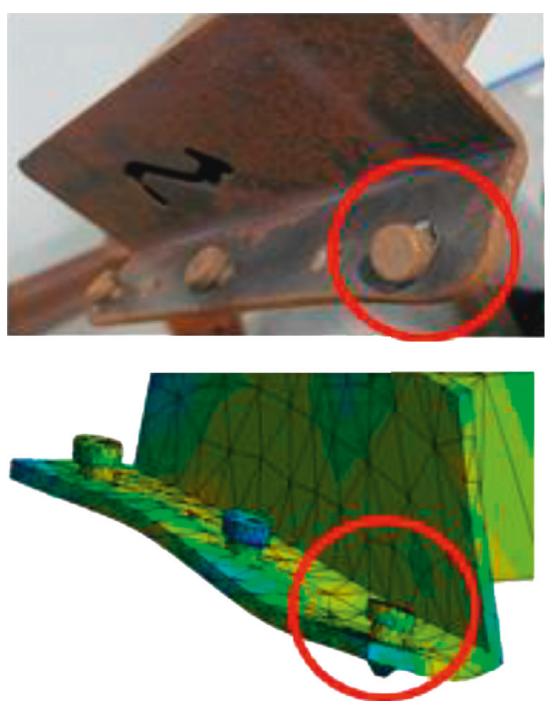

(a)

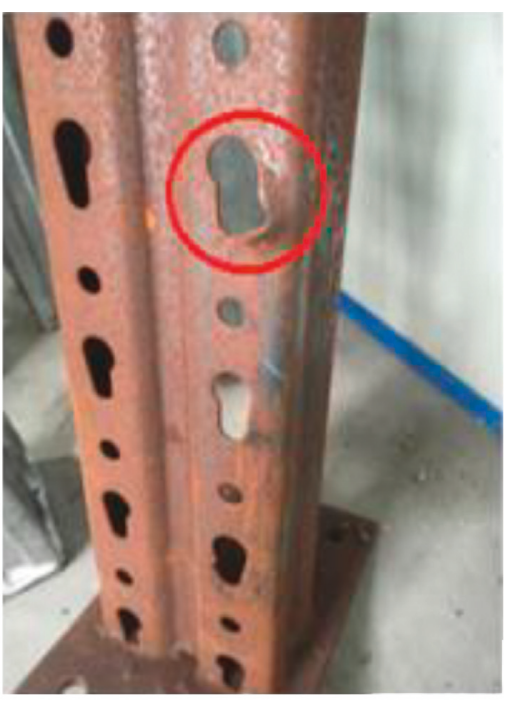

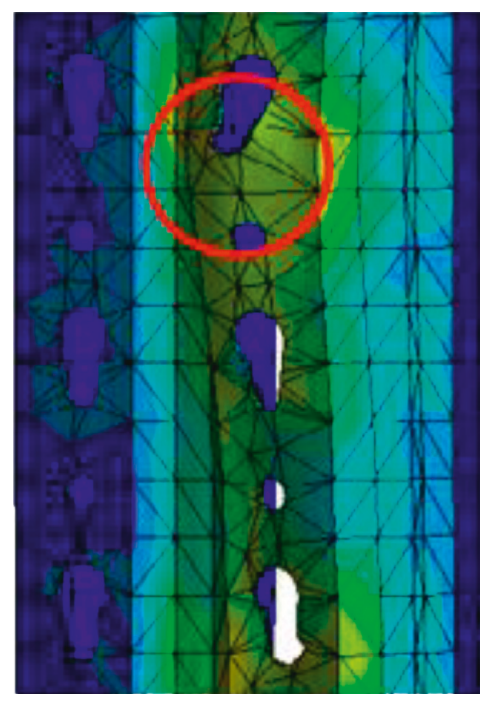

(b)

Figure 6: Comparison of simulation and experimental deformation. (a) Deformation of rivets and beam-end connector and (b) gap of holes.

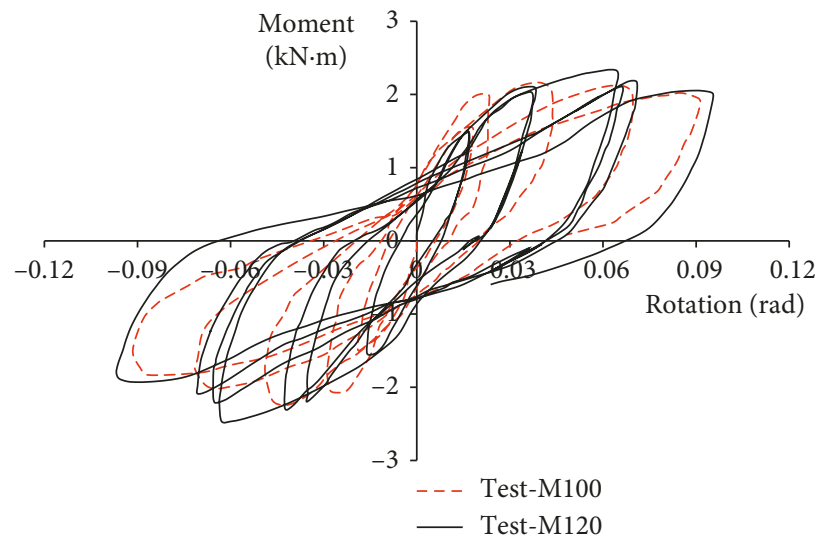

Figure 7: The hysteresis loops.

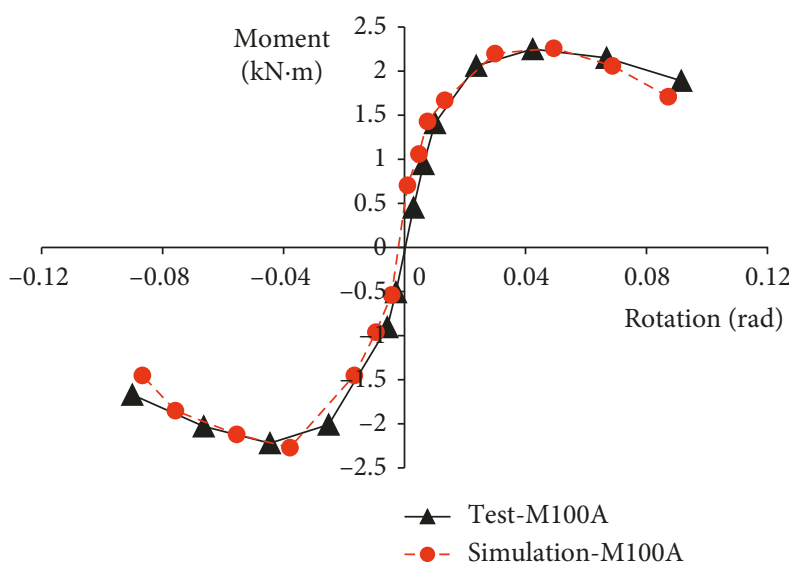

(a)

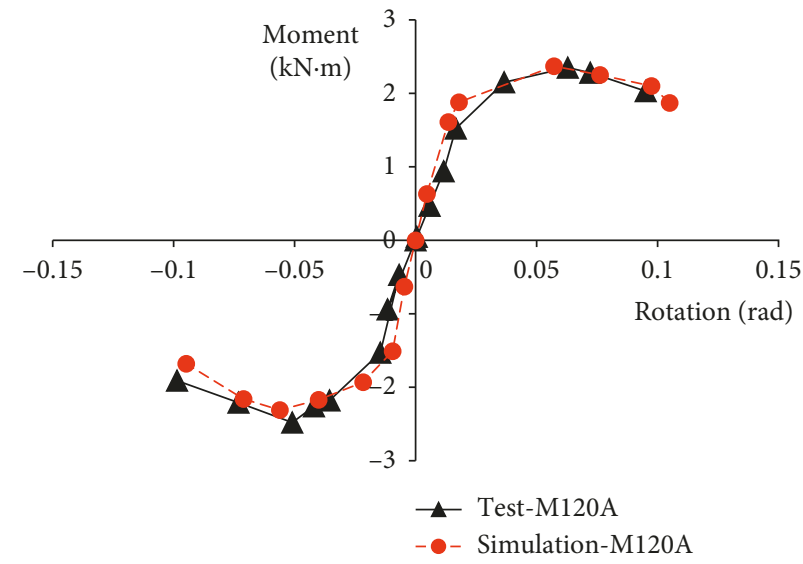

(b)

FIGURE 8: Comparison of experimental and simulation backbone curves. (a) M100 and (b) M120. 


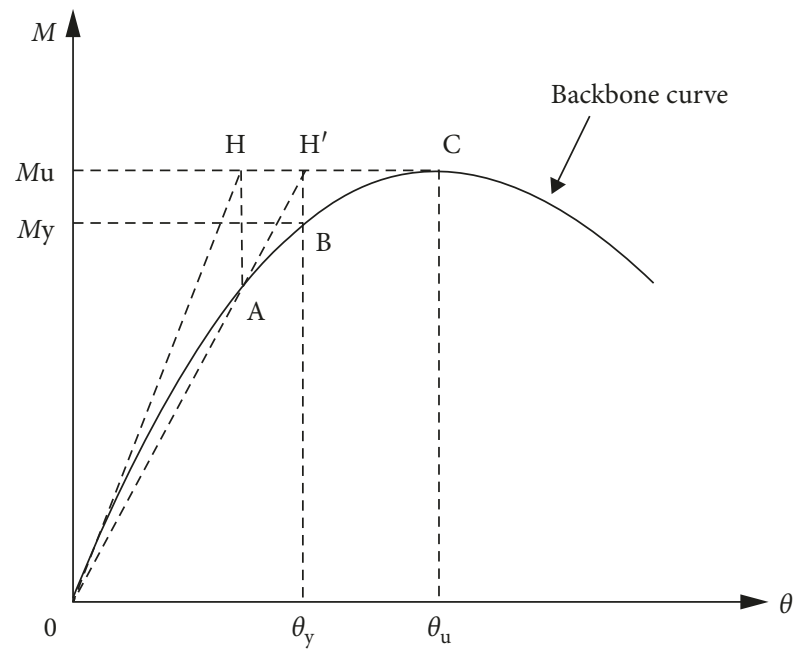

FIGURE 9: Schematic illustration of the general yielding moment method.

TABLe 4: Ductility factors of different connections.

\begin{tabular}{cccc}
\hline & ID & Ductility factor & $\begin{array}{c}\text { Absolute difference } \\
\text { rate }(\%)\end{array}$ \\
\hline & A-1 & 1.764 & 7.45 \\
A & A-2 (standard) & 1.906 & $/$ \\
& A-3 & 2.035 & 6.77 \\
& B-1 & 1.795 & 5.82 \\
B & B-2 (standard) & 1.906 & $/$ \\
& B-3 & 2.009 & 5.40 \\
C & C-1 (standard) & 1.906 & $/$ \\
& C-2 & 2.175 & 14.11 \\
D & D-1 (standard) & 1.906 & $/$ \\
& D-2 & 1.985 & 4.14 \\
& D-3 & 1.912 & $<1 \%$ \\
E & E-1 (standard) & 1.906 & $/$ \\
& E-2 & 2.053 & 7.71 \\
& E-3 & 2.095 & 9.92 \\
F & F-1 (standard) & 1.906 & $/$ \\
& F-2 & 1.875 & 2.46 \\
& F-3 & 1.718 & 9.86 \\
\hline
\end{tabular}

positive unloading stiffness: $\frac{K_{1}}{K_{0}}=-2.427 \ln \left(\frac{\Delta_{1}}{\Delta_{u}^{+}}\right)+3.153$, negative loading stiffness: $\frac{K_{2}}{K_{0}^{\prime}}=3.447 e^{-1.281\left(\Delta_{2} / \Delta_{u}^{+}\right)}$, negative unloading stiffness: $\frac{K_{3}}{K_{0}^{\prime}}=3.102 e^{-1.198\left(\Delta_{3} / \Delta_{u}^{-}\right)}$, positive loading stiffness: $\frac{K_{4}}{K_{0}}=-1.825 \ln \left(\frac{\Delta_{4}}{\Delta_{\mathcal{u}}^{-}}\right)+1.257$.

Similarly, stiffness deterioration rules of other groups were also calculated. It was found that the fitting formulas and degeneracy rules were basically the same. With cyclic

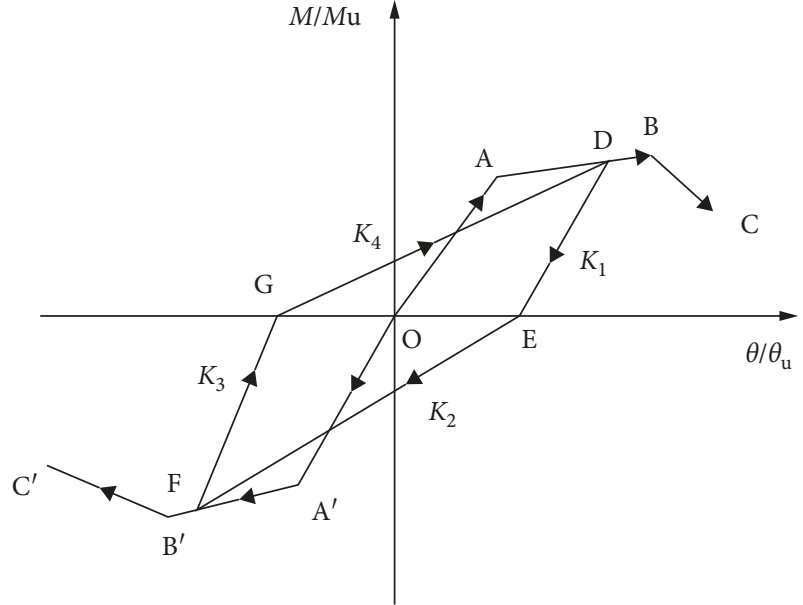

FIgURE 10: Stiffness deterioration calculation diagram.

loading and unloading, stiffness of structures showed obvious deterioration.

After comparing forms of the stiffness deterioration curve fitting formula, it was found that the fitting formulas of the positive unloading and loading stiffness degeneration curves were in the forms of formulas (3) and (4) respectively, while the negative loading and unloading stiffness deterioration curves were in the forms of formulas (5) and (6), respectively. Therefore, the stiffness deterioration can be compared by comparing the values of "a" and " $h$ " in the positive stiffness degeneration. For negative stiffness degeneration, the variation of "d" and "g" is small. Therefore, only the " $c$ " and " $f$ " values need to be compared to evaluate the deterioration rate of negative stiffness. According to calculation results of the positive and negative stiffness degeneration of various beam-column connections, the values of $a, h, c$, and $f$ were extracted, respectively, for analysis of the stiffness deterioration, and the results are shown in Table 5. The absolute difference rate in the table is obtained by taking the standard specimen as the denominator, and the difference is the increase or decrease relative to the previous result. The comparison of the absolute difference is shown in Figure 12.

$$
\begin{aligned}
& \frac{K_{1}}{K_{0}}=-a \ln \left(\frac{\Delta_{1}}{\Delta_{\mathrm{u}}^{+}}\right)+b, \quad(a>0, b>0), \\
& \frac{K_{4}}{K_{0}}=-h \ln \left(\frac{\Delta_{4}}{\Delta_{\mathrm{u}}^{-}}\right)+i, \quad(h>0, i>0), \\
& \left.\frac{K_{2}}{K_{0}^{\prime}}=c e^{-d\left(\Delta_{2} / \Delta_{\mathrm{u}}^{+}\right.}\right), \quad(c>0, d>0), \\
& \left.\frac{K_{3}}{K_{0}^{\prime}}=f e^{-g\left(\Delta_{3} / \Delta_{\mathrm{u}}^{-}\right.}\right), \quad(f>0, g>0) .
\end{aligned}
$$

\section{Parametric Analysis and Assessment}

The FE model that was developed to validate the experimental testing was further extended for parametric analysis. 


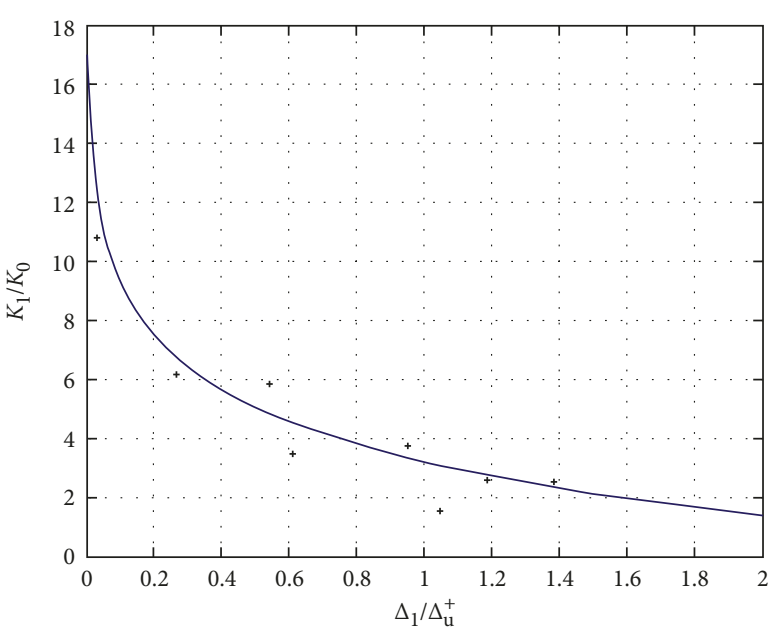

(a)

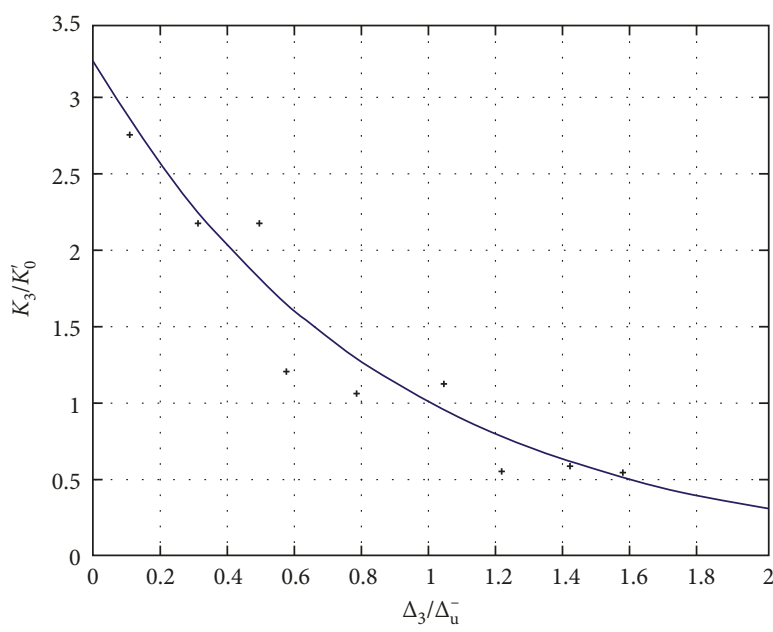

(c)

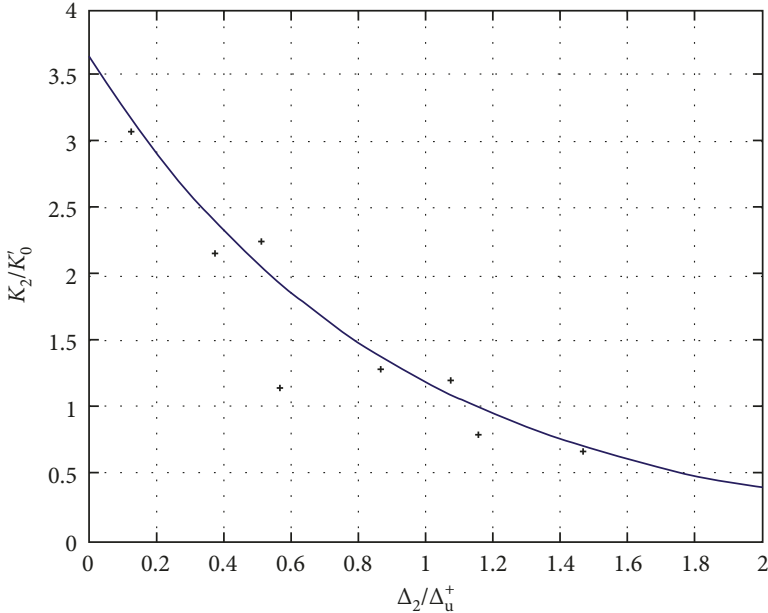

(b)

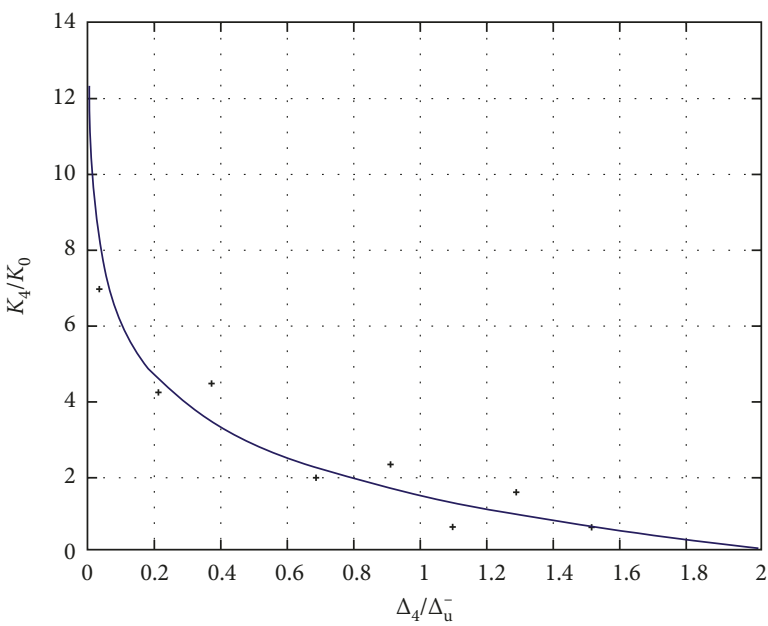

(d)

Figure 11: The stiffness deterioration of BCC under the cyclic loading protocol. (a) Positive unloading stiffness. (b) Negative loading stiffness. (c) Negative unloading stiffness. (d) Positive loading stiffness.

The analyzed parameters are as follows: variation in beam depth, column thickness, and number of rivets in the beamend connector, variation in the thickness of the beam-end connector, variation in the welding position of beams to the beam-end connector, and variation in the clearance between the column and the beam-end connector. Different sizes of specimens were chosen for parametric analysis to observe the connection response.

By comparing ductility factors in Table 4 and stiffness deterioration rules in Table 5 of different combinations, except for the number of rivets, the effect of the thickness of the beam-end connector and clearance on the stiffness deterioration and ductility is slightly greater than the other three factors. The impact of different parameters on the seismic performance of beam-to-column connections was analyzed as follows.

4.1. Effect of Varying Beam Depth, Column Thickness, and Number of Rivets in the Beam-End Connector. With specimens A, the FEM results can be further utilized to assess the effect of beam depth. Compared with B100 beam, the ductility factor of the B80 beam was decreased by $7.45 \%$, while for B120 beam, the ductility factor showed an increase of $6.77 \%$. The positive unloading stiffness deterioration was increased by 9.64\%, and the B120 beam was decreased by about $9.23 \%$. Other stiffness deteriorations showed the same rule, which is compared to the $\mathrm{B} 100$ beam, the stiffness deterioration of the B80 beam decreased more rapidly, and the B120 decreased slowly. To figure out the effect of column thickness and number of rivets in the beam-end connector, specimens $B$ and $C$ showed that increasing the column thickness $(2 \mathrm{~mm}$, $2.5 \mathrm{~mm}$, and $3 \mathrm{~mm}$ ) and number of rivets(from three to four), the ductility increased, and the stiffness deterioration slowed down.

4.2. Effect of Welding Position of Beam to the Beam-End Connector. Parametric analysis was performed on specimens $\mathrm{D}$ in order to assess the effect of welding position of beam to the beam-end connector. The FE analysis of specimens D was performed to assess the effect of the 
TABLE 5: Deterioration comparison of positive and negative stiffness.

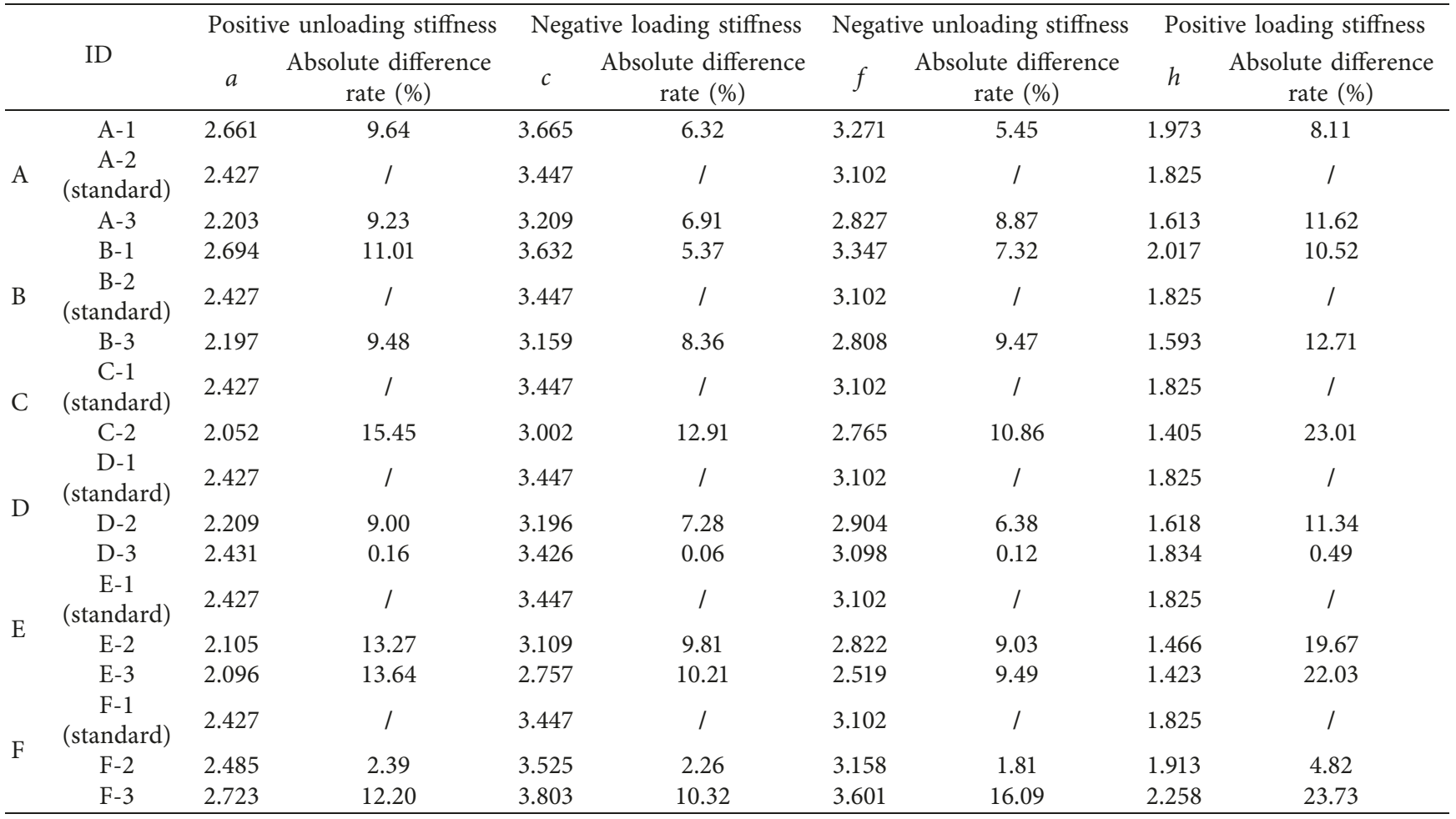

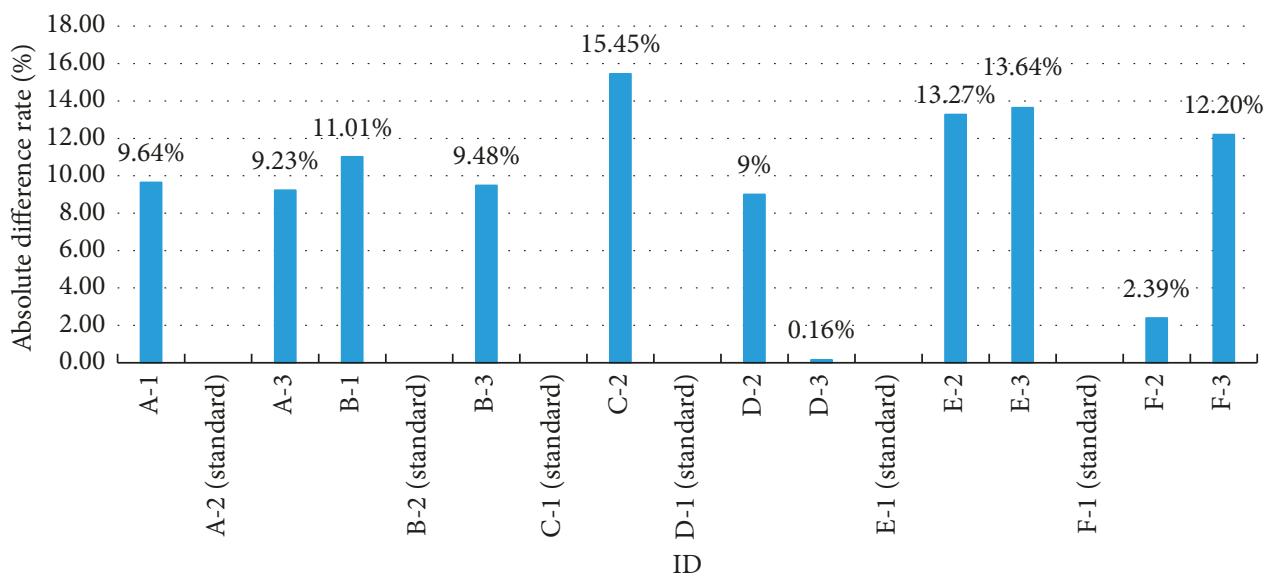

(a)

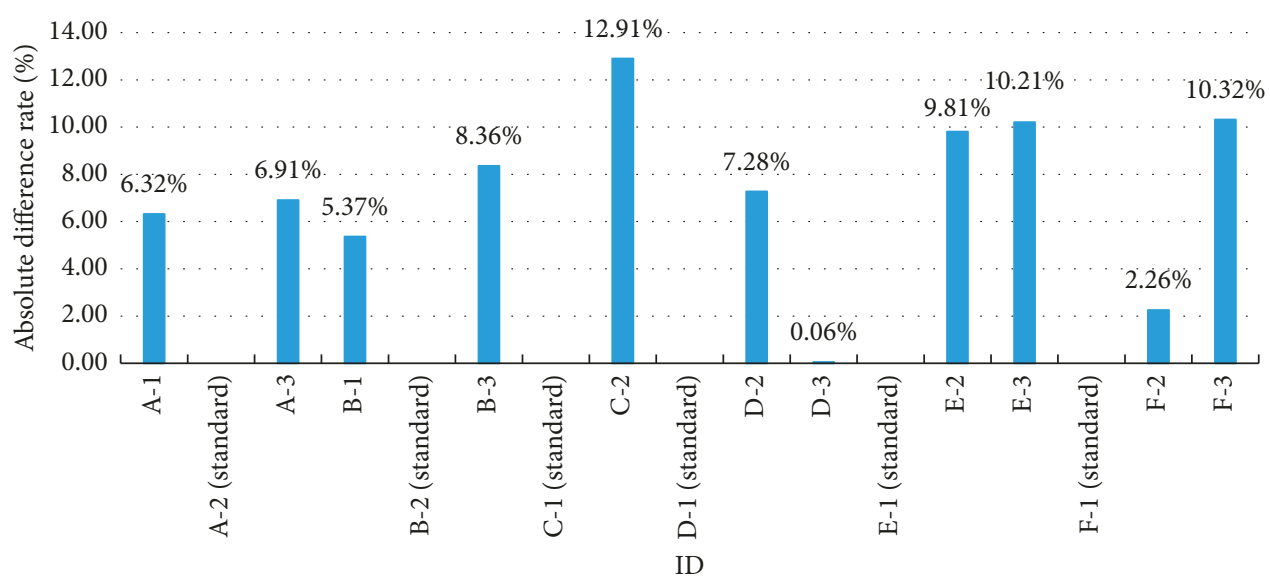

(b)

Figure 12: Continued. 


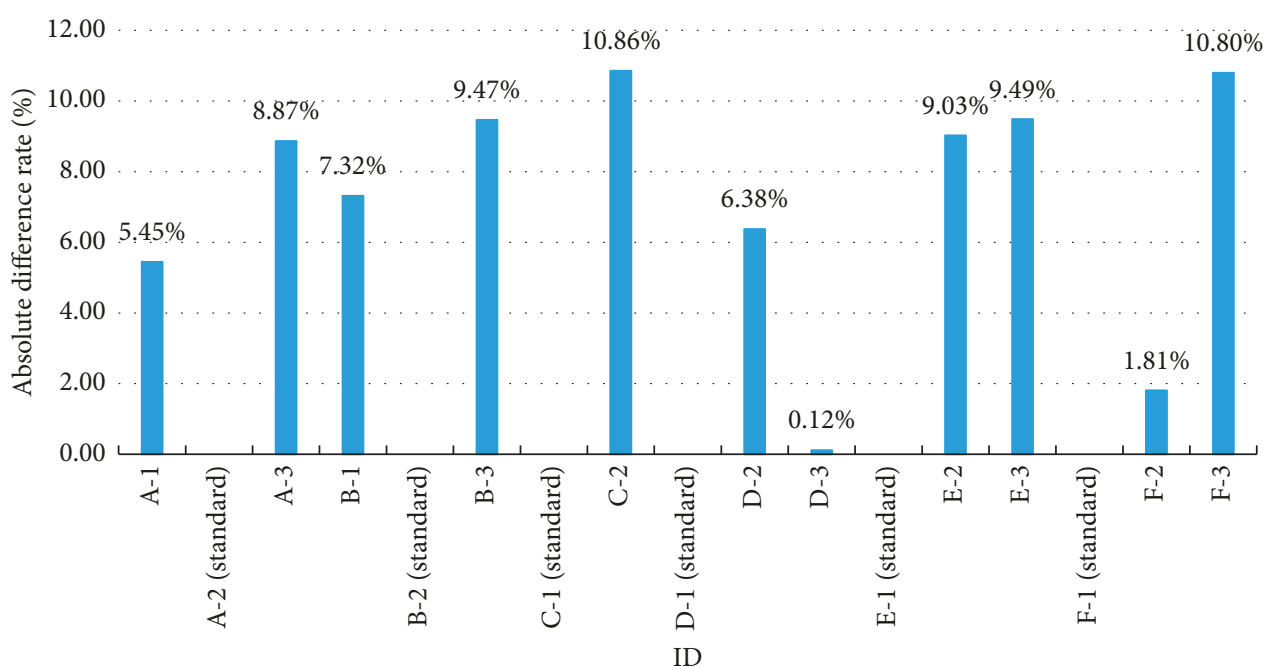

(c)

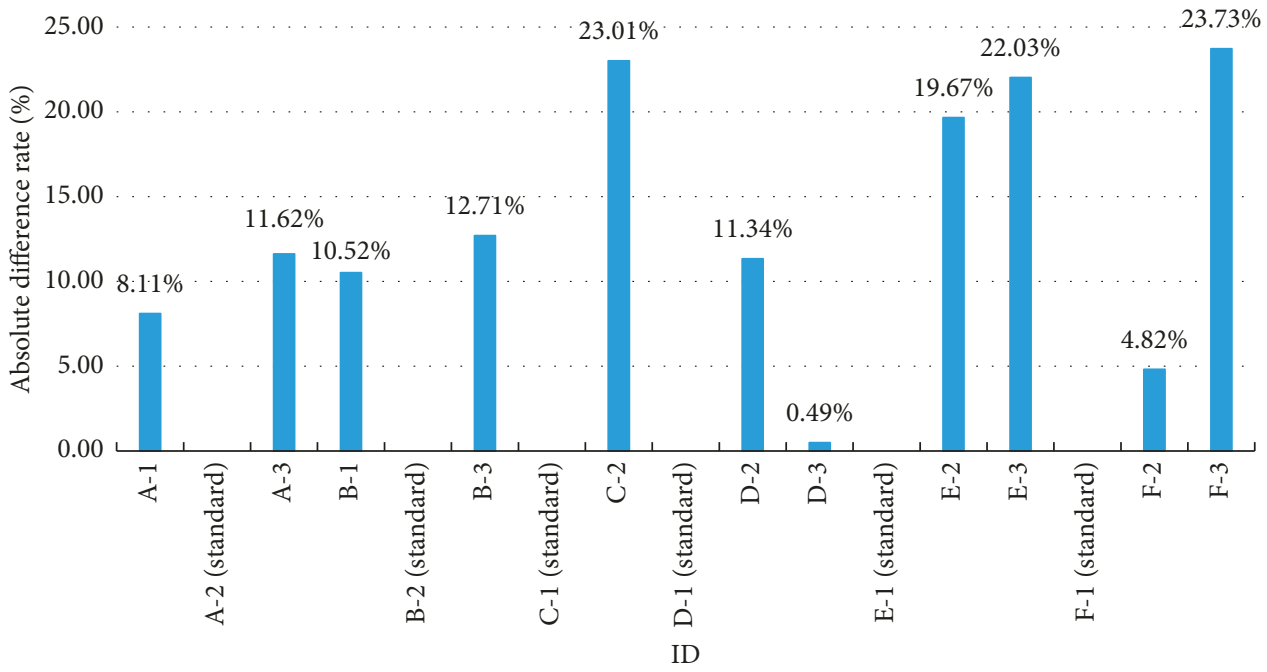

(d)

Figure 12: The comparison of stiffness deterioration. (a) Positive unloading stiffness. (b) Negative loading stiffness. (c) Negative unloading stiffness. (d) Positive loading stiffness.

welding position of beam to the beam-end connector. Judging from the analysis results, when the beam was middle-welded, the seismic performance was the best, when the beam was up-welded and down-welded, the seismic performance was basically the same.

4.3. Effect of Variation in the Thickness of the Beam-End Connector. Parametric analysis was performed on specimens $\mathrm{E}$ in order to assess the effect of the thickness of the beam-end connector. In specimens $\mathrm{E}, 4 \mathrm{~mm}, 5 \mathrm{~mm}$, and $6 \mathrm{~mm}$ thick beam-end connectors were used. Increasing the thickness of the beam-end connector from $4 \mathrm{~mm}$ to $5 \mathrm{~mm}$ and $6 \mathrm{~mm}$ (specimen E) significantly affected the ductility (increased by $7.71 \%$ and $9.92 \%$ ) and the stiffness deterioration of the connection. Taking the positive unloading stiffness as a base, the $5 \mathrm{~mm}$ and $6 \mathrm{~mm}$ thickness were decreased by $13.27 \%$ and $13.64 \%$, respectively. In general, the stiffness appeared a greater deterioration.

4.4. Effect of Variation in the Clearance between Column and the Beam-End Connector. Clearance between the column and the beam-end connector was $1 \mathrm{~mm}, 2 \mathrm{~mm}$, and $3 \mathrm{~mm}$ in the FE analysis of specimens F. Increasing clearance from $1 \mathrm{~mm}$ to $2 \mathrm{~mm}$, the ductility factor showed a smaller increase $(2.46 \%)$ and slight stiffness deterioration appeared $(\leq 5 \%)$. When increasing clearance from $1 \mathrm{~mm}$ to $3 \mathrm{~mm}$, significant decrease in the ductility factor was observed (9.86\%). At the same time, stiffness had a greater deterioration.

\section{Conclusion}

In this paper, the cyclic responses of different combinations of beam-to-column connections were investigated in order 
to study the influence of different parameters on the dynamic behavior of the beam-to-column connections. These parameters included column thickness, beam depth, thickness of the beam-end connector, and the welding position of beam to the beam-end connector. Utilizing the cantilever test method, cyclic loading tests were conducted to explore their dynamic behaviors. By comparison with ductility factors and stiffness deterioration index, based on different configurations of beam-to-column connections except for the number of rivets, the effect of the thickness of the beam-end connector and clearance on the stiffness deterioration and ductility was slightly greater than the other three factors. Increasing beam-end connector thickness from $4 \mathrm{~mm}$ to $5 \mathrm{~mm}$ and $6 \mathrm{~mm}$ significantly improved the ductility and the stiffness had a slighter deterioration. When increasing clearance from $1 \mathrm{~mm}$ to $2 \mathrm{~mm}$, the ductility factor showed a smaller increase, and slight stiffness deterioration appeared. But when increasing clearance from $1 \mathrm{~mm}$ to $3 \mathrm{~mm}$, the ductility factor showed significant decrease and stiffness had a greater deterioration. In summary, increasing thickness of the beam-end connector can significantly improve the seismic performance of connections. Although increasing the clearance between the column and the beamend connector is better for the assembling of steel pallet rack, it needs to be elaborately selected because it greatly reduced the performance of connections. The results in our paper seem to be preliminary; however, it has been observed that the dynamic behavior of SPR BCCs relies on geometrical parameters. The increasing demand of cold-formed thinwalled steel in high-rise rack needs to explore reliable and simple methods of accurate prediction of the behavior of storage racks and contents, which should be in a close coordination and interaction with the experimental test.

\section{Data Availability}

The data used to support the findings of this study are all included in the article.

\section{Conflicts of Interest}

The authors declare that they have no conflicts of interest.

\section{Acknowledgments}

This paper has been funded by the National Key R\&D Program of China (2017YFB1304000), technology innovation program of Shanghai Municipal Science and Technology Commission (17DZ2283800), and Minhang Science and Technology Foundation (2017mH205).

\section{References}

[1] C. Bernuzzi and M. Simoncelli, "An advanced design procedure for the safe use of steel storage pallet racks in seismic zones," Thin-Walled Structures, vol. 109, pp. 73-87, 2016.

[2] F. D. Markazi, R. G. Beale, and M. H. R. Godley, "Experimental analysis of semi-rigid boltless connectors," ThinWalled Structures, vol. 28, no. 1, pp. 57-87, 1997.
[3] Rack Manufacturers Institute (RMI), Specification for the Design, Testing and Utilization of Industrial Steel Storage Rack, Material Handling Industry, MH16.1 2012, Charlotte, NC, USA, 2012.

[4] EN15512, Steel Static Storage Systems-Adjustable Pallet Racking Systems-Principles for Structural Design, European Committee for Standardization, Brussels, Belgium, 2009.

[5] Standards Australia, Steel Storage Racking, AS4084, Standards Australia, Sydney, Australia, 2012.

[6] K. M. Bajoria and R. S. Talikoti, "Determination of flexibility of beam-to-column connectors used in thin walled coldformed steel pallet racking systems," Thin-Walled Structures, vol. 44, no. 3, pp. 372-380, 2006.

[7] X. Zhao, T. Wang, Y. Chen, and K. S. Sivakumaran, "Flexural behavior of steel storage rack beam to-upright connections," Journal of Constructional Steel Research, vol. 99, pp. 161-175, 2014.

[8] C. Bernuzzi and C. A. Castiglioni, "Experimental analysis on the cyclic behaviour of beam-to-column joints in steel storage pallet racks," Thin-Walled Structures, vol. 39, no. 10, pp. 841-859, 2001.

[9] F. Gusella, G. Lavacchini, and M. Orlando, "Monotonic and cyclic tests on beam-column joints of industrial pallet racks," Journal of Constructional Steel Research, vol. 140, pp. 92-107, 2018.

[10] Z. Tang and N. Chouw, "Experimental investigation on uplift behaviour of mortar-free interlocking columns," in Proceedings of New Zealand Society for Earthquake Engineering (NZSEE), Auckland, New Zealand, March 2014.

[11] S. N. R. Shah, N. H. Ramli Sulong, R. Khan, M. Z. Jumaat, and M. Shariati, "Behavior of industrial steel rack connections," Mechanical Systems and Signal Processing, vol. 70-71, pp. 725-740, 2016.

[12] N. Baldassino and C. Bernuzzi, "Analysis and behaviour of steel storage pallet racks," Thin-Walled Structures, vol. 37, no. 4, pp. 277-304, 2000.

[13] F. Gusella, M. Orlando, and A. Vignoli, "Effects of pinching in the hysteresis loop of rack connections," in Proceedings of the XVII Convegno ANIDIS, Pistoia, Italy, September 2017.

[14] A. Carlos, "Structural properties of connections for rack structures," in Connections in Steel Structures V, Federico Santa Maria University, Valparaiso, Chile, June 2004.

[15] L. Yin, G. Tang, M. Zhang, B. Wang, and B. Feng, "Monotonic and cyclic response of speed-lock connections with bolts in storage racks," Engineering Structures, vol. 116, pp. 40-55, 2016.

[16] E. Mashaly, M. El-Heweity, H. Abou-Elfath, and M. Osman, "Finite element analysis of beam-to-column joints in steel frames under cyclic loading," Alexandria Engineering Journal, vol. 50, no. 1, pp. 91-104, 2011.

[17] FEM 10.2.08, The Design of Static Steel Pallet Racking in Seismic Conditions, FEM Racking \& Shelving Product Group, West Bromwich, UK, 2011.

[18] B. Zhu, Seismic Test of Structure, Earthquake Express, Beijing, China, 1989, in Chinese. 


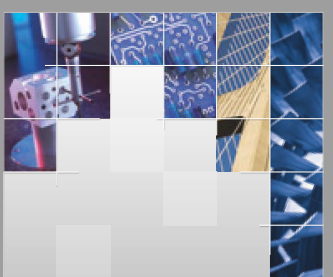

\section{Enfincering}
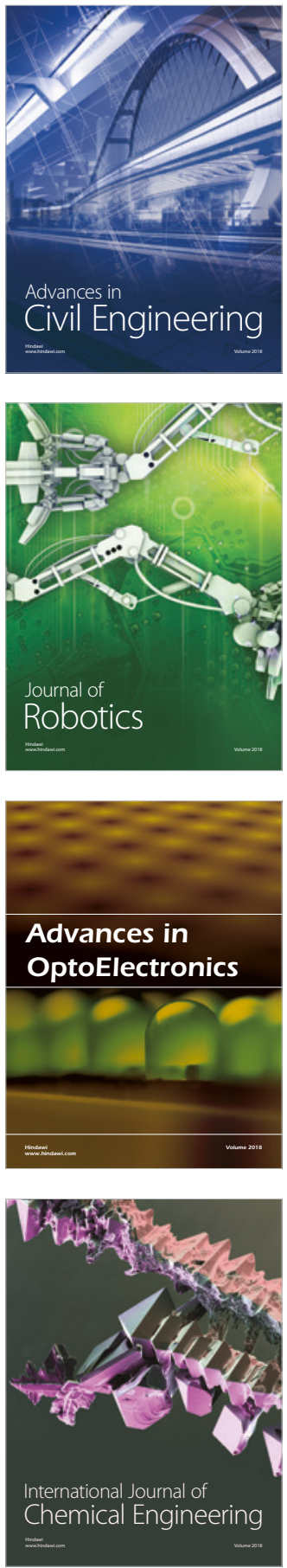

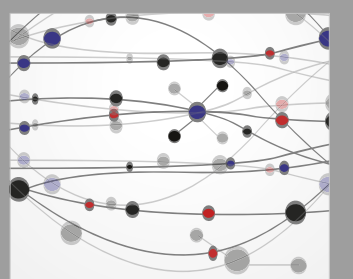

\section{Rotating \\ Machinery}

The Scientific World Journal

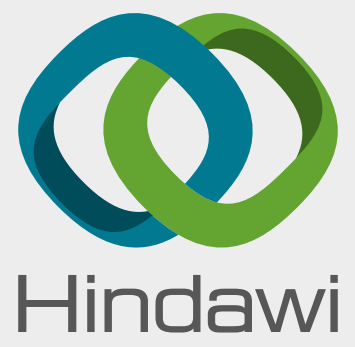

Submit your manuscripts at

www.hindawi.com
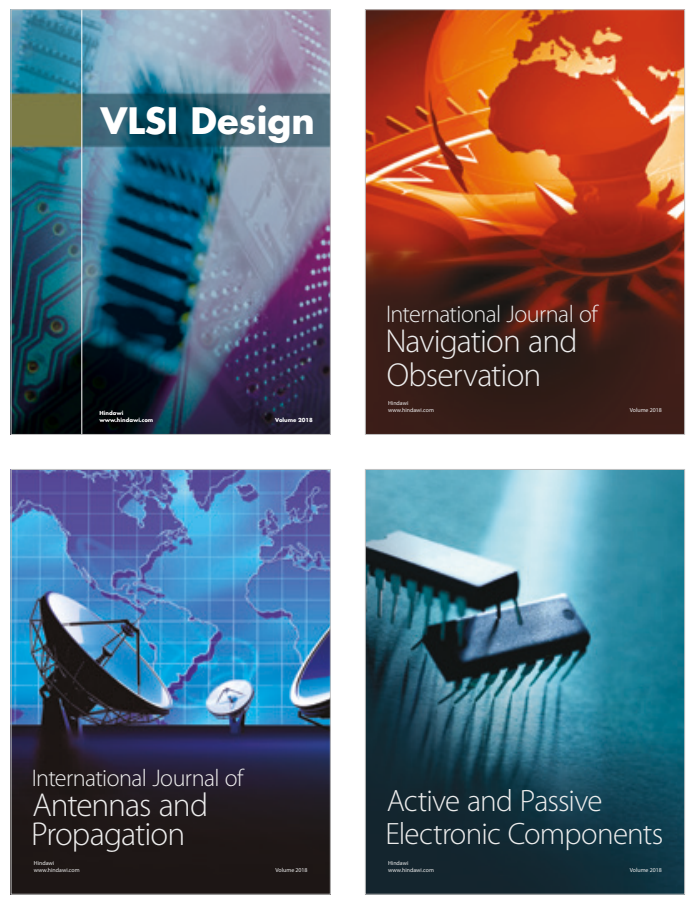
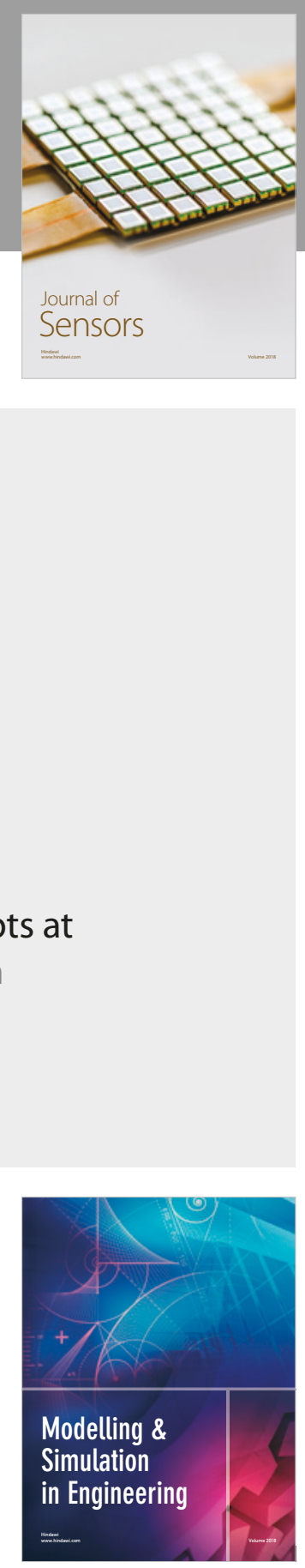

\section{Advances \\ Multimedia}
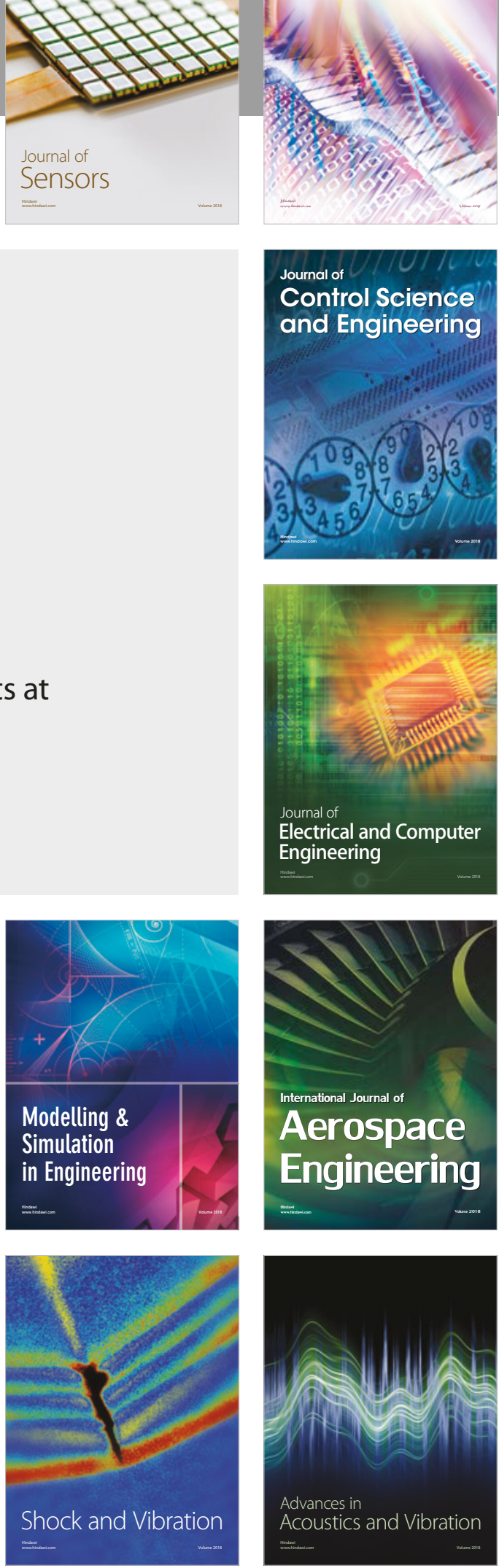